\title{
Level of Water Governance in Schools and its Effect on Student Participation in Education
}

\author{
Wambeye K.M ${ }^{1}$, Wasike, D.W ${ }^{2}$, Obino, P.O ${ }^{3}$ \\ ${ }^{I}$ Department of Educational Planning and Management, Kibabii University, Kenya \\ ${ }^{2}$ Department of Science \&amp; Mathematics Education, Kibabii University, Kenya \\ ${ }^{3}$ Department of Social Sciences, Kibabii University, Kenya
}

\begin{abstract}
Adequate access to water, hygiene and sanitation is every human's and child's right. These do not reflect national policies aspirations and are not adequate to student's needs, affecting their health, well-being, performance and participation at school in Kenya. A cross-sectional survey design was adopted to sample from boarding schools that were sampled to take part in a study conducted in Bungoma County in the Western region of Kenya.Stratified sampling was employed in choosing the Schools while questionnaires, interview schedules, document analysis and focus groups were used to gather data. The model was not able to significantly predict the level of water governance in schools and its effect on student participation in education and hence concluded that every boarding secondary school should develop a drinking water access plan. This study provides an empirical pattern of participation in education influenced by WASH in schools.
\end{abstract}

Key Words: water governance, Hygiene, sanitation, Participation

\section{INTRODUCTION}

$\mathrm{W}$ ater is the most important natural resource, indispensable for life and at the same time the backboneof growth and prosperity for mankind. According to estimations by the United Nations (2009) more people die presently due to insufficient access to safe water and basic sanitation than in military conflicts, Because of the importance of water services for the economic growth of a country and the wellbeing of its population. United Nation Development programme (UNDP-2010) recommends that governments should provide investments equivalent to $1 \%$ of the national product in the provision of water. The growing demands for water against the limited natural endowment and its increasing scarcity could result in armed conflicts and pandemics if infrastructure and management of water is not improved.

A joint report by United Nations Children's Fund (2016) and World health organization(2016) through monitoring programme for water supply, sanitation and hygiene shows that 570 million children go to school every day without safe water and Nearly 900 million children worldwide lacked basic hygiene service at their school. Further the report reveals that quarter of secondary schools had no hygiene service and Over 620 million children worldwide lacked a basic sanitation service at their school. Globally, 69\% of schools had a basic drinking water service, $66 \%$ of schools had a basic sanitation and 53\% of schools had a basic hygiene service in 2016.

The negative impact of insufficient of water services on education and on productivity of the population is equally huge. The receipt of a good quality education is one of the most important factors in enabling children to fulfil potential in later life and reduce poverty. (Abadzi, 2009) Increased educational attainment is also associated with substantial health gains especially on child health in future generations including reduction in child mortality. The link between contaminated drinking water and disease risk is well accepted and it is clear that the main risk falls on young children (Risebro, et al, 2012). Clearly, reducing student absenteeism is important to improving educational attainment and consequent poverty alleviation. Thus, water is a key determining aspect for economic growth in a country and for the wellbeing of its population. Many rural households have to spend hours per day fetching water from unsecured sources where water quality is suspect. The burden is borne by women and children for whom may be there is no time to attend school regularly because of the obligation to secure water for the household (UNICEF, 2016).

The Government of Kenya (GOK) has continuously been committed to increasing provision of safe, potable, and affordable water to all its citizens as an integral part of its Social and Economic Growth through its policies which included: Sessional Paper No. 1 of 1999 on National Policy on Water Resources Management and Development, The Water Act 2002 which had three (3) primary objectives namely: improving the management of water services, access to water and sanitation services and enhancing accountability for water resources management through decentralization of service delivery. The Kenya Constitution (2010), entrenched the water and sanitation in the Bill of Rights, effectively making them human rights in Article 43(i) (b) \& (d) of the Kenya Constitution. Primarily, the Constitution acknowledges access to clean and safe water as a basic human right and assigns the responsibility for water supply and sanitation service provision to county governments. The water rights are envisioned to improve the health status and livelihoods of vulnerable populations, specifically, women, children and those with limited access to clean water during flooding, drought or another natural disaster. 
A school with adequate WASH ${ }^{1}$ services has a functional and reliable water system that provides safe, sufficient water for all needs of the school, especially for toilet use, hand-washing and drinking. It has a sufficient number of toilets for students and teachers and the toilets are private, safe, accessible, clean and separate for boys and girls. Adequate WASH in schools service caters for the needs of the entire school population, including small children, girls of menstruation age, children with disabilities and staff. School water, sanitation and hygiene seem inadequate in Kenyan schools in terms of the number of facilities and hygiene practices. Policy standards exist to guide adequate school WASH, including gender segregated and minimum acceptable ratios of students to toilet options for sanitation. Internationally accepted standards also guide programs on how to assess the quality and quantity of available water and improved hygiene in schools. Despite available guidance, some school standards and designs do not conform to international standards and undermine structural safety and sustainability. Improving WASH facilities in schools could dramatically improve the quality of education across the globe, evidence suggests that schools with functioning WASH systems achieve better education outcomes through improvements in school attendance and achievement (Adukia, 2016 and Naidoo 2013).

\section{THE LITERATURE}

Water governance refers to the political, social, economic and administrative systems in place that influence water's use and management. Essentially, who gets what water, when and how, and who has the right to water and related services, and their benefits. Governing water includes the formulation, establishment and implementation of water policies, legislation and institutions, and clarification of the roles and responsibilities of government, civil society and the private sector in relation water resources and services.

The outcomes depend on how the stakeholders act in relation to the rules and roles that have been taken or assigned to them. Increasing water scarcity is one of the globe's greatest challenges. As local demand for water rises above supply in many regions, the effective governance of available water resources will be key to achieving water security, fairly allocating water resources and settling related disputes. Sound governance will also be essential for the attainment of the Sustainable Development Goals (SDGs). Poor resource management, corruption, inappropriate institutional arrangements, bureaucratic inertia, insufficient human capacity and shortages of finances for investments also undermine the effective governance of water in many places around the world. These are also the challenges to be addressed by governance reforms.

Water governance side sustainability remains a serious challenge. Deficient institutional and administrative structures, lack of political will, accountability and lack of stakeholder engagement are part of the problem. Other challenges of governance include; Low prioritization of WASH services by school decision makers and parents; lack of administrative capacity at the school level; and, weak incentives of decision makers to provide sustainable WASH services, or of parents and others to monitor and encourage such provision. A recent study in Kenya showed that one-third of the newly established community-managed water systems stop functioning within the first three years after completion (Kwena and Moronge 2015). Functionality issues are often a consequence of community groups struggling to put in place adequate governance and management systems, as well as lacking linkage to and the oversight of local governments (Transition Authority, 2015). Elsevier (2016) noted the following governance challenges among the community water providers in Kenya: Lack of management capacity. Disconnection between the responsible government institutions community water providers. Not conversant with the regulatory framework and, therefore, put little emphasis on linking community groups with the relevant stakeholders and putting in place appropriate (and compliant) management models.

In planning and locating water sources in the rural areas, the following issues related to project management are considered for successful operation (Water Kenya report, 2006): Tribal issues: conflicts between tribes are Common in Kenya. Selection of the location shall be decided after a series of dialogues with the people concerned. Religion: Due to religion, vandalism of the constructed facilities is also common. The people concerned will select members of a water user committee through election. Cultural issues: Nomads dependent on livestock move seasonally from place to place. Provision of water points may cause social-cultural problems among people. Assessment of public needs for water: People's needs for water assessed carefully. Where water supply is planned to be constructed by other undertaker's water point construction is not recommended. Formation of water user committee; to ensure sustainability of the water supply scheme, a water user committee responsible for operation and management of the scheme will be organized within the community concerned. Public involvement and participation: To increase opportunities of the public involvement to the schemes, it is more preferable to ask the community to provide work forces during construction. Investment costs to be borne by beneficiaries: beneficiaries shall meet the investment costs. Women's involvement in the stage of design, construction and operation: Women play an important role in handling water in their daily lives and should therefore be involved in all stages of the scheme development. Hygiene and health education: It is of vital importance to instruct people on the need for safe and potable water, sanitation, water borne diseases related to pubic hygiene and health through seminar, meetings, movies, etc.

1 Water, Sanitation and Hygiene 
This study is based on two theories; systems theory initially developed by Bertalanffy (1968) and the theory of Institutional Departure created by Vincent Tinto (1975). These two theories are concerned with drop out of school with the main focus on different sets of predictors. A system by definition is composed of interrelated parts or elements. This is true for all systems: mechanical, biological, and social. Every system has at least two elements, and these elements are interconnected. The school is an open system which is viewed as a transformation model. It is in a dynamic relationship with its environment, it receives various inputs, transforms these inputs in some way, and exports outputs. The open system theory also emphasizes the necessary dependence of any organization upon its environment. Everything in an environment is a complete system on its own. WHO (2002) affirms that the physical school environment encompasses the school building and all its contents including physical structures, infrastructure, furniture, and the use and presence of chemicals and biological agents; the site on which a school is located; and the surrounding environment including the air, water, and materials with which children may come into contact, as well as nearby land uses, roadways and other hazards.

Provision of safe and sufficient water, sanitation, and hygiene practices from the elements are basic necessities for a healthy physical learning environment. The physical school environmenthas a strong influence on children's health, the environment is one of the primary determinants of children's health: contaminated water supplies can result in diarrhoea. The theory of institutional created by Vincent Tinto (1975) with the main focus on college; the theory states, that drop out from educational facility can be seen as a process, which takes place over a long period of time. During this time many complex interactions between the individual, the academic and social systems take place. The final version of Tinto's Model of Institutional Departure (1993) states that schools consist of two systems: academic and social. Students need to be integrated into both systems to persist in their academic institutions. Academic integration can be measured by the students' grade performance and intellectual development, while social integration is measured by students' interaction with other students in the school.

\section{School Enrolment in Kenya}

Since independence the education sector in Bungoma County has expanded rapidly with a substantial increase in the number of educational institutions. At the primary level, the GER has consistently registered more than $100 \%$ over the period under review as shown in table 2.1. The GER greater than $100 \%$ indicates existence of overage and underage children enrolled in primary schools. At secondary level, promotion rates are relatively high with form one recording the highest and form three the lowest (100.7\% and $90.1 \%$ respectively). Girls recorded better promotion rates than boys in all the classes. The promotion rates above $100 \%$ are attributed to re-entry policy for girls at form one and two. The repetition rates range between $0.6 \%$ and $3.2 \%$ with form four recording the highest while form one recorded the lowest. Male students remain more vulnerable to drop out across all classes of secondary schools compared to the female counterparts. From table 2.2 in the year 2014 Bungoma County had a gross enrolment of 78 per cent with a net enrolment of 63.4 per cent that is lower than the national enrolment rate of 70.5 per cent in secondary schools.

Table 1: Gross and Net Enrolment Rates for secondary in Kenya (2009-2014)

\begin{tabular}{|c|c|c|c|c|c|c|}
\hline Year & 2009 & 2010 & 2011 & 2012 & 2013 & 2014 \\
\hline GER & $41.90 \%$ & $45.70 \%$ & $47.80 \%$ & $50.50 \%$ & $54.30 \%$ & $58.20 \%$ \\
\hline NER & $33.10 \%$ & $36.00 \%$ & $38.80 \%$ & $41.70 \%$ & $44.50 \%$ & $47.40 \%$ \\
\hline
\end{tabular}

Source: Ministry of Education, Science and Technology

Table 2: Secondary School Enrollment (2014)

\begin{tabular}{|c|c|c|c|c|c|c|c|c|c|}
\hline \multirow{2}{*}{ Level } & \multicolumn{3}{|c|}{ Enrollment } & \multicolumn{3}{c|}{$\begin{array}{c}\text { GrossEnrollment } \\
\text { Rate (GER) }\end{array}$} & \multicolumn{3}{c|}{$\begin{array}{c}\text { Net Enrollment } \\
\text { Rate(NER) }\end{array}$} \\
\cline { 2 - 10 } & Boys & Girls & Total & $\begin{array}{c}\text { Bo } \\
\text { ys }\end{array}$ & $\begin{array}{c}\text { Gir } \\
\text { ls }\end{array}$ & $\begin{array}{c}\text { Tot } \\
\text { al }\end{array}$ & $\begin{array}{c}\text { Boy } \\
\text { s }\end{array}$ & $\begin{array}{c}\text { Gi } \\
\text { rls }\end{array}$ & $\begin{array}{c}\text { To } \\
\text { tal }\end{array}$ \\
\hline $\begin{array}{c}\text { Bungo } \\
\text { ma }\end{array}$ & $\begin{array}{c}56,66 \\
2\end{array}$ & $\begin{array}{c}48,32 \\
4\end{array}$ & $\begin{array}{c}104,98 \\
6\end{array}$ & $\begin{array}{c}71 . \\
9 \%\end{array}$ & $\begin{array}{c}60 . \\
8 \%\end{array}$ & $\begin{array}{c}66 . \\
3 \%\end{array}$ & $\begin{array}{c}58.2 \\
\%\end{array}$ & $\begin{array}{c}50 \\
.0\end{array}$ & $\begin{array}{c}54 . \\
1 \\
\%\end{array}$ \\
\hline $\begin{array}{c}\text { Nation } \\
\text { al }\end{array}$ & $\begin{array}{c}1,213, \\
266\end{array}$ & $\begin{array}{c}1,118, \\
431\end{array}$ & $\begin{array}{c}2,331, \\
697\end{array}$ & $\begin{array}{c}61 . \\
5 \%\end{array}$ & $\begin{array}{c}56 . \\
0 \%\end{array}$ & $\begin{array}{c}58 . \\
7 \%\end{array}$ & $\begin{array}{c}49.6 \\
\%\end{array}$ & $\begin{array}{c}45 \\
.2\end{array}$ & $\begin{array}{c}47 . \\
\%\end{array}$ \\
$\%$
\end{tabular}

Source: Ministry of Education, Science and Technology.

From table 2.3 showing the national internal Efficiency Indicators for Primary and Secondary Education (2014) at secondary level, promotion rates are relatively high with form one recording the highest and form three the lowest $(97.6 \%$ and $104.3 \%$ for boys and Girls respectively). Girls recorded better promotion rates than boys in all the classes. The promotion rates above $100 \%$ are attributed to re-entry policy for girls at form one and two. The repetition rates range between $0.6 \%$ and $3.2 \%$ with form four recording the highest while form one recorded the lowest. Male students remain more vulnerable to drop out across all classes of secondary schools compared to the female counterparts. The data shows negative dropout rates for girls in form one and two implying that the number of students re-joining the system having left at some point is greater than the number exiting in 2014.

Table 3: Internal Efficiency Indicators for Secondary Education (2014)

\begin{tabular}{|c|c|c|c|c|c|c|c|c|c|}
\hline & \multicolumn{3}{|c|}{ Promotion Rate } & \multicolumn{3}{|c|}{ Repetition Rate } & \multicolumn{3}{|c|}{ Dropout Rate } \\
\hline & $\begin{array}{l}\text { Bo } \\
\text { ys }\end{array}$ & $\begin{array}{c}\text { Girl } \\
\mathrm{s}\end{array}$ & $\begin{array}{c}\text { Tot } \\
\text { al }\end{array}$ & $\begin{array}{l}\text { Bo } \\
\text { ys }\end{array}$ & $\begin{array}{c}\text { Girl } \\
\mathrm{s}\end{array}$ & $\begin{array}{c}\text { Tot } \\
\text { al } \\
\end{array}$ & $\begin{array}{l}\text { Bo } \\
\text { ys }\end{array}$ & $\begin{array}{c}\text { Girl } \\
\mathrm{s}\end{array}$ & Total \\
\hline $\begin{array}{l}\text { For } \\
\mathrm{m} 1\end{array}$ & $\begin{array}{l}97 . \\
6 \%\end{array}$ & $\begin{array}{l}104 \\
.3 \%\end{array}$ & $\begin{array}{l}100 \\
.7 \%\end{array}$ & $\begin{array}{c}0.7 \\
\%\end{array}$ & $\begin{array}{c}0.5 \\
\%\end{array}$ & $\begin{array}{c}0.6 \\
\%\end{array}$ & $\begin{array}{l}1.7 \\
\%\end{array}$ & $\begin{array}{c}- \\
4.8\end{array}$ & $-1.3 \%$ \\
\hline $\begin{array}{l}\text { For } \\
\mathrm{m} 2\end{array}$ & $\begin{array}{l}98 . \\
6 \%\end{array}$ & $\begin{array}{l}101 \\
.2 \%\end{array}$ & $\begin{array}{l}99 . \\
8 \%\end{array}$ & $\begin{array}{c}1.4 \\
\%\end{array}$ & $\begin{array}{c}1.1 \\
\%\end{array}$ & $\begin{array}{c}1.2 \\
\%\end{array}$ & $\begin{array}{c}0.0 \\
\%\end{array}$ & ${ }^{-} .2$ & $-1.0 \%$ \\
\hline $\begin{array}{l}\text { For } \\
\text { m3 }\end{array}$ & $\begin{array}{l}88 . \\
9 \%\end{array}$ & $\begin{array}{l}91 . \\
6 \%\end{array}$ & $\begin{array}{l}90 . \\
1 \%\end{array}$ & $\begin{array}{c}2.7 \\
\%\end{array}$ & $\begin{array}{c}1.9 \\
\%\end{array}$ & $\begin{array}{c}2.3 \\
\%\end{array}$ & $\begin{array}{c}8.4 \\
\%\end{array}$ & $\begin{array}{c}6.5 \\
\%\end{array}$ & $7.5 \%$ \\
\hline $\begin{array}{l}\text { For } \\
\mathrm{m} 4\end{array}$ & $\begin{array}{c}\mathrm{N} / \\
\mathrm{A}\end{array}$ & $\begin{array}{l}\mathrm{N} / \\
\mathrm{A}\end{array}$ & $\begin{array}{c}\mathrm{N} / \\
\mathrm{A}\end{array}$ & $\begin{array}{c}4.1 \\
\%\end{array}$ & $\begin{array}{c}2.2 \\
\%\end{array}$ & $\begin{array}{c}3.2 \\
\%\end{array}$ & $\begin{array}{c}\text { N/ } \\
\text { A }\end{array}$ & $\begin{array}{c}\mathrm{N} / \\
\mathrm{A}\end{array}$ & N/A \\
\hline
\end{tabular}

Source: Ministry of Education, Science and Technology 
The enrolment for primary schools in Bungoma County stood at 519,362 compared to the National enrollment which stood at 9,950,746 table 2.4. In their study on Internal Efficiency in Bungoma County Secondary Education Ngome and Kikechi (2015) found that dropout rate in the county in 2013 for secondary school was $3.1 \%$ for Boys and $3.5 \%$ for Girls. The study further revealed that Out of 4,884 boys and 5,108 girls who enrolled in form one in 2010, only 3,657 boys (75\%) and 3,452 girls $(68 \%)$ completed the four years of the secondary education Cycle in 2013.

\section{METHODOLOGY}

The study adopted a cross-sectional survey design; the crosssectional research is a research approach in which the researchers investigate the state of affairs in a population at a certain point in time (Wayne and Curt, 2015). This method was chosen because it is relatively faster and inexpensive (Creswell, 2013). The population targeted consisted of 83 Boarding secondary schools and comprised of the students $(78,481)$, Teachers $(3,238)$, principals (83), Public Health Officers nine (9) and the Quality Assurance and Standards officers nine (9). The Boarding secondary school level was chosen because a majority of the student resides at the school using WASH facilities. Stratified random sampling was used to select Boys boarding schools and Girls Boarding school. A total number of secondary schools in Bungoma County was first grouped into Boys Boarding, Girls Boarding, Mixed Boarding, Mixed Day \& Boarding, Girls Day \& Boarding, Boys Day \& Boarding, Girls Day, Mixed Day, Mixed Day schools to get the sample frame as shown in table 3.2.

Table 4: Category of Boarding Secondary Schools in Bungoma County

\begin{tabular}{|c|c|}
\hline School Category & Number \\
\hline Boys Boarding & 24 \\
\hline Girls Boarding & 22 \\
\hline Mixed Boarding & 37 \\
\hline Total & 83 \\
\hline
\end{tabular}

This study applied Krejcie and Morgan (1970) table for determining the sample size to select a representative sample for each category of the stratified population. Krejcie and Morgan developed a formula and table for determining sample size for a given population for easy reference applied where the population is finite as in this case. Their sample size calculation was based on $\mathrm{p}=0.05$ where the probability of committing type I error is less than $5 \%$ or $\mathrm{p}<0.05$.

$s=\frac{X^{2} N P(1-P)}{d^{2}(N-1)+X^{2} P(1-P)}$ where:

$s=$ required sample size.

$X^{2}=$ the table value of chi-square for 1 degree of freedom at the desired confidence level (3.841).

$N=$ the population size.
$P=$ the population proportion (assumed to be .50 since this would provide the maximum Sample size).

$d=$ the degree of accuracy expressed as a proportion (.05).

Based on Krejcie and Morgan's table for determining sample size, a sample size of sixty five (65) boarding secondary schools were chosen to take part in the study.Stratified sampling was employed in choosing the Girls boarding secondary schools, Boys Boarding Secondary schools and Mixed Boarding Secondary Schools. Random sampling was used to sample Five (5) form four students and Two (2) teachers that have been in the Station for more than Five years to take part in the study from each school participating in the study. Three (3) Quality Assurance and Standards officers, three (3) Public Health Officers were purposively sampled to participate in the study.Stratified random sampling was considered suitable in this case because the population is divided into different strata or groups.

Table 5: Proportionate sampling of Boarding Secondary schools

\begin{tabular}{|c|c|c|c|c|c|}
\hline $\mathrm{H}$ & Stratum & $\begin{array}{c}\text { Populatio } \\
\mathrm{n}\left(N_{h}\right)\end{array}$ & $\sqrt{N_{h}}$ & $\begin{array}{c}a_{h} \\
=\frac{\sqrt{N_{h}}}{\sum \sqrt{N_{h}}}\end{array}$ & $\begin{array}{c}\text { Sample } \\
\left(n_{h}\right)\end{array}$ \\
\hline 1 & Boys Boarding & 24 & 4.89 & 0.3123 & 20 \\
\hline 2 & Girls Boarding & 22 & 4.69 & 0.2995 & 19 \\
\hline 3 & Mixed Boarding & 37 & 6.08 & 0.3883 & 25 \\
\hline & TOTAL & 83 & 15.66 & 1.000 & 65 \\
\hline
\end{tabular}

Table 6: Sampling of respondents

\begin{tabular}{|c|c|c|c|}
\hline $\mathrm{H}$ & Stratum & Population $\left(N_{h}\right)$ & Sample $\left(n_{h}\right)$ \\
\hline 1 & Students & 28,821 & 325 \\
\hline 2 & Teachers & 3238 & 130 \\
\hline 3 & Principals & 83 & 65 \\
\hline 4 & $\begin{array}{l}\text { Quality Assurance } \\
\text { and Standards } \\
\text { officers }\end{array}$ & 9 & 3 \\
\hline \multirow[t]{2}{*}{5} & $\begin{array}{l}\text { Public Health } \\
\text { Officers }\end{array}$ & 9 & 3 \\
\hline & Total & 32,160 & 526 \\
\hline
\end{tabular}

The data was collected using questionnaires for students, teachers and principals of Bungoma County. Interview schedules were used for Principals, Public Health Officers and Quality Assurance and Standards officers.

The study tested the Null hypothesis that there is no effect of water governance to participation in education

Content validity of the research instruments was initiated at the design stage, as instrumentation is a major threat to internal validity. Kombo and Tromp (2006) emphasize that validity is the degree to which results obtained from the 
analysis of the data actually represent the phenomenon under study; in this case the validity of the content of the study was sorted out. The research instruments were able to depict what they are measuring and what is supposed to measure.

This study employed Triangulation techniques in dealing with validity, in order to strengthen the validity of evaluation data and findings, this study collected data through several sources: questionnaires, interviews and observations. Gathering data through one technique can be questionable, biased and weak. However, collecting information from a variety of sources and with a variety of techniques can confirm findings. Therefore, if we obtain the same results, the researcher becomes sure that the data is valid.

Reliability is a measure of the degree to which research instrument yields consistent results or data after repeated trials (Mugenda and Mugenda 2003; Orodho, 2004). This is achieved by carrying out several pilot surveys at intervals. A comparison between answers obtained from the first and second attempts are subjected to Pearson product moment coefficient analysis.in this study reliability of $r=+0.73$ was obtained.

The Independent variables are shown in table 3.5. Kombo and Tromp (2006) assert that these are the explanatory factors which the researcher thinks explain variation in the dependable variable.

Table 7: Independent variables

\begin{tabular}{|c|c|c|}
\hline Variable & Indicators & Measure \\
\hline $\begin{array}{l}\text { Stakeholders } \\
\text { engagement: }\end{array}$ & $\begin{array}{l}\text { Interaction with the stakeholders coded as } \\
(5=\text { very frequently, } 4=\text { frequently } 3=\text { Often, } \\
2=\text { Sometimes } 1=\text { Never }) \\
\text { related matters coded as }(5=\text { very frequently, } \\
4=\text { frequently } 3=\text { Often, } 2=\text { Sometimes } 1= \\
\text { Never })\end{array}$ & Interval \\
\hline $\begin{array}{l}\text { Water policy } \\
\text { Objective: }\end{array}$ & $\begin{array}{c}\text { Convergence of water policy objectives } \\
\text { coded as }(5=\text { Not an obstacle, } 4=\text { somewhat } \\
\text { an obstacle, } 3=\text { obstacle, } 2=\text { Important } \\
\text { obstacle } 1=\text { Major obstacle }) \\
\end{array}$ & \\
\hline $\begin{array}{c}\text { Coherence and } \\
\text { consistence: }\end{array}$ & $\begin{array}{c}\text { Policy coherence and consistency on water } \\
\text { coded as }(5=\text { Not an obstacle, } 4=\text { somewhat } \\
\text { an obstacle, } 3=\text { obstacle, } 2=\text { Important } \\
\text { obstacle } 1=\text { Major obstacle })\end{array}$ & \\
\hline $\begin{array}{l}\text { Capacity in } \\
\text { water } \\
\text { management } \\
\text { in schools: } \\
\end{array}$ & $\begin{array}{c}\text { Capacity challenges in water management } \\
\text { coded as }(5=\text { Not an obstacle, } 4=\text { somewhat } \\
\text { an obstacle, } 3=\text { obstacle, } 2=\text { Important } \\
\text { obstacle } 1=\text { Major obstacle }) \\
\end{array}$ & \\
\hline $\begin{array}{c}\text { Financial } \\
\text { sustainability }\end{array}$ & $\begin{array}{c}\text { Financial sustainability of water management } \\
\text { coded as }(5=\text { Not an obstacle, } 4=\text { somewhat } \\
\text { an obstacle, } 3=\text { obstacle, } 2=\text { Important } \\
\text { obstacle } 1=\text { Major obstacle) }\end{array}$ & \\
\hline
\end{tabular}

\section{RESULTS}

Water governance refers to systems that are involved in decision-making about water management and water service delivery. Ultimately, water governance determines who gets what water, when and how. Effective governance entails participatory approaches that are shaped by stakeholders at the local level. The principals were invited to carry out a survey using the questionnaires. The questionnaires comprised the six sub-indicators allocated different weights. Interaction of the School with the stakeholders for management of water. obstacles that hinder the effective contribution of stakeholders engagement to decision making to water management in schools. Obstacles that hinder the convergence of water policy objectives in schools. Capacity challenges that hinder the performance of water management in schools.

Stakeholder relationships are viewed as fundamental to the provision of water to citizens, and a broad range of actors from the private and non-profit sectors. I have adopted the following definition of stakeholder engagement: the process by which any person or group who has an interest or stake in a water-related topic is involved in the related activities and decision-making and implementation processes. The person or group may be directly or indirectly affected by water policy and/or have the ability to influence the outcome positively or negatively (OECD, 2015). The study revealed that Interaction with the Water Service Providers for example NZOWASCO in management of water in schools is poor since 43(72.9\%) have never interacted directly or indirectly, only 12(20.3\%) showed frequent interaction. Seventy percent $41(70 \%)$ of the schools have never Interaction with the County Government in management of water in schools, it only $18(31 \%)$ of the respondents who have interacted. There is no Interaction with the Water Regulator for management of water in schools. There is some level of Interaction between schools and financial actors (donors, international financial institutions, investors) in management of water in schools 24(40.7\%). Interaction with the non -government organization in management of water in schools is $13(21.2 \%)$. School also Interact with the Advisors (e.g. engineering, consulting firms) in management of water in schools 13(21. 2\%). The important role stakeholders play from different institutional settings can contribute to effective, efficient and inclusive water management. Governments now acknowledge that water policies, however well-intentioned, need stakeholder engagement for their implementation on the ground (Akhmouchet al, 2016).

\section{Obstacles}

While stakeholder engagement processes vary greatly across places, common obstacles have been identified that hinder the effective contribution of stakeholders engagement to decision making to water management in schools have been identified: Results from the survey revealed a number of obstacles that hinder stakeholders engagement at the school level in the management of water. 


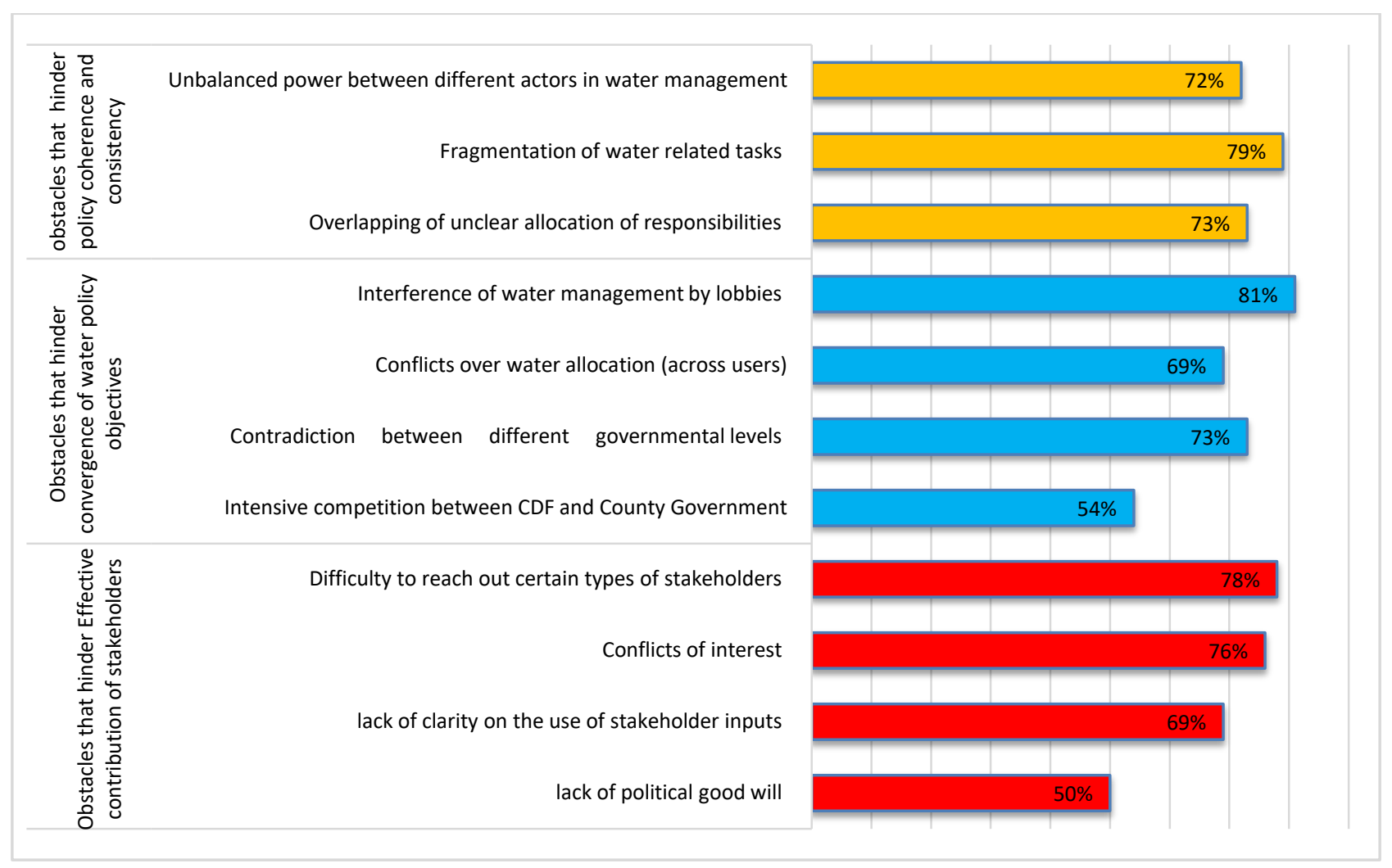

Figure 1'

Fifty percent $29(50 \%)$ cited lack of political will and leadership needed to shift the balance of power among stakeholders, including towards actors that may not share the same intentions, perspectives and interests; Sixty nine $38(69 \%)$ of the respondents felt that another obstacle is lack of clarity on the use of stakeholder inputs (e.g., to build consensus, to take decisions, to share information, to raise awareness), which can result in mistrust and consultation "fatigue"; seventy six percent $45(76 \%)$ of the respondents cited Conflicts of interest and consultation "capture", especially when certain groups of actors and lobbies are better organized to voice their concerns as another obstacle. Institutional fragmentation with overlapping mandates and conflicting goals, possibly leading to inadequate co-operation across authorities, water-related sectors and scales was also cited as an obstacle38(69\%); Difficulty to reach out certain types of stakeholders was also cited as an obstacle by seventy eight percent $40(78 \%)$ of the respondents as shown in figure 1.1 .

The study also explored Obstacles that hinder the convergence of water policy objectives in schools in water management, the following were identified; Intensive competition between county government and constituency development fund (CDF) within the locality (political rivalries etc.)32(54\%) has affected the provision of water in schools. Another obstacle that was identified is Contradiction between different governmental levels recommendations/directives in the management of water $43(73 \%)$. Also identified as an obstacle is Conflicts over water allocation (acrossusers) 41(69\%). Finally Interferenceof water management by lobbies $48(81 \%)$. The study established the following obstacles hinder policy coherence and consistency on water in schools. Overlapping of unclear allocation of responsibilities 42(73\%). Fragmentation of water related tasks 47 (79\%). Unbalanced power between different actors in water management (e.g. county Government vs. National Government) 44 (72\%).

Good governance of the water sector remains a priority at National and County levels in the quest to ensure the progressive realization of the right to water and sanitation. Effective governance entails participatory approaches that are shaped by stakeholders at the local level. Governance on school WASH includes monitoring budgets offering goods and services, associated issues of accountability. Governance is the sum of the many ways individuals and institutions, public and private, manage their common affairs. I this study lack of School interaction with the stakeholders for management of water is a major barrier for managing school WASH. Non Interaction with the Water Service Providers e.g. NZOWASCO in management of water in schools 43(72.9\%).

The study established that most schools have insufficient technical skills to be able to run a water system efficiently, ensure its O\&M and allocate clear roles and responsibilities within the school. The personnel hired to attend to water are 
in many cases not qualified for their functions. The lack of capacity, adequate processes and oversight can lead to mismanagement. I schools where they share water with the community members abuse their position for private gains. With no by-laws, or codes of conduct in place, being in charge of operating the water system can be used as a means of power, for example by cutting off some community members, serving others for free or pocketing part of the money.

The schools are not conversant with the regulatory framework and, therefore, put little emphasis on linking with the relevant stakeholders and putting in place appropriate measures. Interaction with the National Government in management of water in schools stands at $41(69.5 \%)$, there is no Interaction with the Water Regulator for management of water in schools $59(100 \%)$. Therefore, schools often have little exposure to their rights linked with providing water supply services and the rules and regulations to comply with (Lucie, et al 2016). Consequently, they end up operating in isolation and, outside the sector's accountability systems, there is no control of the quality of the services provided or supervision to safeguard human rights standards and government responsibility for fulfilling the right to water is undermined. It also excludes schools from government financial and/or technical support mechanisms.

\section{Multiple regression for School Water Governance}

Multiple regression analysis was conducted to test if School water governance in schools significantly predicted student drop out from schools.

Table 8:Model Summary ${ }^{\mathrm{b}}$ for School Water Governance

\begin{tabular}{|c|c|c|c|c|}
\hline & $\mathrm{R}$ & R Square & $\begin{array}{c}\text { Adjusted R } \\
\text { Square }\end{array}$ & $\begin{array}{c}\text { Std. Error of } \\
\text { the Estimate }\end{array}$ \\
\hline & $.233^{\mathrm{a}}$ & .054 & -.055 & 3.586 \\
\hline
\end{tabular}

Source: Field data, 2019

a. Predictors: (Constant), Obstacles hinder the financial sustainability of water management in schools, Water stakeholders Interaction, Obstacles that hinder the convergence of water policy objectives in schools, Obstacles that hinder stakeholder's engagement, Capacity challenges that hinder the performance of water management in schools, Obstacles that hinder policy coherence and consistency on water in schools.

b. Dependent Variable: The total rate of student dropping from school

Table 9: ANOVA ${ }^{\mathrm{a}}$ for School Water Governance

\begin{tabular}{|c|c|c|c|c|c|c|}
\hline \multicolumn{2}{|c|}{} & $\begin{array}{c}\text { Sum of } \\
\text { Squares }\end{array}$ & df & $\begin{array}{c}\text { Mean } \\
\text { Square }\end{array}$ & F & Sig. \\
\hline & Regression & 38.263 & 6 & 6.377 & .496 & $.808^{\text {b }}$ \\
\hline Residual & 668.598 & 52 & 12.858 & & \\
\hline Total & 706.860 & 58 & & & \\
\hline
\end{tabular}

Source: Field data, 2019

a. Dependent Variable: The total rate of student dropping from school

b. Predictors: (Constant),

Water stakeholders Interaction;

Obstacles that hinder stakeholder's engagement;
Obstacles that hinder the convergence of water policy objectives in schools;

Obstacles that hinder policy coherence and consistency on water in schools; Capacity challenges that hinder the performance of water management in schools;

Table 10: Coefficients ${ }^{\mathrm{a}}$ for Water Governance in School

\begin{tabular}{|c|c|c|c|c|c|}
\hline & \multicolumn{2}{|c|}{$\begin{array}{l}\text { Unstandardize } \\
\text { d Coefficients }\end{array}$} & \multirow{2}{*}{$\begin{array}{c}\begin{array}{c}\text { Standar } \\
\text { dized } \\
\text { Coeffic } \\
\text { ients }\end{array} \\
\text { Beta }\end{array}$} & \multirow[b]{2}{*}{$\mathrm{t}$} & \multirow[b]{2}{*}{ Sig } \\
\hline & B & $\begin{array}{l}\text { Std. } \\
\text { Error }\end{array}$ & & & \\
\hline (Constant) & $\begin{array}{c}5.49 \\
8\end{array}$ & 2.091 & & 2.629 & .011 \\
\hline $\begin{array}{l}\text { Water stakeholders } \\
\text { Interaction }\end{array}$ & .766 & .951 & .114 & .806 & .424 \\
\hline $\begin{array}{c}\text { Obstacles that hinder } \\
\text { stakeholder's engagement }\end{array}$ & -.057 & .566 & -.019 & -.100 & .921 \\
\hline $\begin{array}{l}\text { Obstacles that hinder the } \\
\text { convergence of water policy } \\
\text { objectives in schools }\end{array}$ & -.814 & .762 & -.313 & -1.069 & .290 \\
\hline $\begin{array}{l}\text { Obstacles that hinder policy } \\
\text { coherence and consistency } \\
\text { on water in schools. }\end{array}$ & .383 & .875 & .135 & .437 & .664 \\
\hline $\begin{array}{l}\text { Capacity challenges that } \\
\text { hinder the performance of } \\
\text { water management in } \\
\text { schools }\end{array}$ & .178 & .660 & .062 & .270 & .788 \\
\hline
\end{tabular}

Source: Field data, 2019

Standard multiple linear regressions at $\alpha=.05$ was used to examine the efficacy of water governance on student dropout in schools table $4.23 ; 4.24$ and 4.25 , represents the results of regression.. The independent variable in the study was water governance The dependent variable was student drop out. The null hypothesis was: $H_{0}$ : There is no effect of water governance to participation in education. Preliminary analysis was conducted to assess whether the assumption of multi collinearity, outliers, Normality, homoscedasticity and independent of residuals were met. The Model was not able to significantly predict Student drop out from schools. (F $(6,52)$ $=.496, \mathrm{p}<.808)$, with an $\mathrm{R}^{2}$ of .054 . The coefficient of determination $\mathrm{R}^{2}$, which is the proportion of variance in the dependent variable (Student dropout rate) that can be explained by the independent variables (water governance), that our independent variables explain $5.2 \%$ of the variability of the dependent variable (dropout rate), When water governance in schools is coded as Water stakeholders Interaction ( 1 = "Never" 2 = "Sometimes", 3 = "Often" $4=$ "frequently" $5=$ "very frequently"). Obstacles that hinder stakeholder's engagement and coded as ( 1 = "Major obstacle", 2 = "Important obstacle", 3 = "Not an obstacle ", 4 = "obstacle ", 5 = "somewhat an obstacle". Obstacles that hinder the convergence of water policy objectives in schools coded as (1 = "Major obstacle", 2 = "Important obstacle", 3 = "Not an obstacle ", 4 = "obstacle ", 5 = "somewhat an obstacle"). Obstacles that hinder policy coherence and consistency on water in schools. ( 1 = "Major obstacle", 2 = "Important obstacle", 3 = "Not an obstacle ", $4=$ "obstacle ", $5=$ "somewhat an obstacle"). Capacity challenges that hinder the 
performance of water management in schools coded as $(1=$ "Major obstacle", 2 = "Important obstacle", 3 = "Not an obstacle ", 4 = "obstacle ", 5 = "somewhat an obstacle").

The analysis shows that Water stakeholders Interaction in schools did not significantly predict student drop out from school $($ Beta $=.114, \mathrm{t}(52)=.424)$, also the analysis revealed that Obstacles that hinder stakeholder's engagement in school did not significantly predict student drop out from school $($ Beta $=-.019, \mathrm{t}(52)=.921)$. Obstacles that hinder the convergence of water policy objectives for water in schools did not significantly predict student drop out from school $($ Beta $=-.313, \mathrm{t}(52)=.290)$. Obstacles that hinder policy coherence and consistency on water in schools did not significantly predict student drop out from school (Beta = .135 , $\mathrm{t}(52)=.664)$. Capacity challenges that hinder the performance of water management in schools did not significantly predict student drop out from school $($ Beta $=$ $.062, \mathrm{t}(52)=.788)$.

Therefore the study fails to reject the null hypothesis.

\section{SUMMARY ON MODELING}

The study identified the predictors of school participation, the mathematical model for Water Governance in schools was also developed to predict participation in education.

$$
Y_{D r}=\alpha_{w g}+\emptyset_{s i}+\emptyset_{s e}+\emptyset_{p o}+\emptyset_{c c}+\emptyset_{w m}
$$

Where:

$Y_{D r}=$ Student dropout rate in a school

$\alpha_{w g}=$ Regression constant for Water Governance

$\emptyset_{s i}=$ Coefficient of Water stakeholders Interaction

$\emptyset_{s e}=$ Coefficient of Obstacles that hinder stakeholder's engagement

$\emptyset_{p o}=$ Coefficient of Obstacles that hinder the convergence of water policy objectives in schools

$\emptyset_{c c}=$ Coefficient of Obstacles that hinder policy coherence and consistency on water in schools.

$\emptyset_{w m}=$ Coefficient of Capacity challenges that hinder the performance of water management in schools

Using coefficient on table 4.25

$$
\begin{aligned}
& Y_{D r} \\
& =5.498 \\
& +.766 \emptyset_{s i}-.057 \emptyset_{s e}-.814 \emptyset_{p o}+.383 \emptyset_{c c}+.178 \emptyset_{w m}
\end{aligned}
$$

This study has shown that stakeholders Interaction in school, Obstacles that hinder stakeholder's engagement, Obstacles that hinder the convergence of water policy objectives in schools, Obstacles that hinder policy coherence and consistency on water in schools and Capacity challenges that hinder the performance of water management in schools was not statistically significant therefore this model does not tracks the patterns of student participation in education fairly well.

\section{CONCLUSION}

The results from the multiple linear regression indicated that the level of water governance in schools and its effect on student participation in education in schools is not statistically significant variables and predictors of student participation in education. There are other factors within school as well as outside school that affects student's participation in education.

The limitation to the study was Non-response which is a particular problem affecting cross-sectional studies and can result in bias of the measures of outcome. This is a particular problem when the characteristics of non-responders differ from responders. Recall bias can occur if the study asks participants about past exposures (Yu IT, 2012). Stratified sampling was adopted to ensure adequate statistical power among strata's this eliminated the bias. Secondly information bias is problem associated with Cross sectional survey, Answering a questionnaire or responding agreeing to be interviewed is frequently used to collect a substantial proportion of the information in these studies. In which case, care was taken in interpreting and drawing conclusions based on such information, as there is a tendency for respondents to provide what they believe to be socially acceptable answers rather than the truth,

It is thus recommended that every boarding secondary school should develop a drinking water access plan to identify strengths and opportunities for improvement in providing access to and consumption of drinking water. This can be achieved by developing a list of recommended actions to address policy and practice needs for providing access to and consumption of drinking water.

\section{REFERENCES}

[1] Abadzi H (2009) Instructional Time Loss in Developing Countries: Concepts, Measurement, and Implications. World Bank Res Obser 24: 267-290.

[2] Akhmouch. A. and Clavreul. D. (2016). Stakeholder Engagement for Inclusive Water Governance: "Practicing What We Preach" with the OECD Water Governance Initiative. Organization for Economic Co-operation and Development (OECD).

[3] Creswell, J. W. (2013). Research design: Qualitative, quantitative, and mixed methods approach. Sage Publications, Incorporated.

[4] Dillingham, R. \&. Guerrant, R. L. (2004). Childhood Stunting: Measuring and Stemming the Staggering Costs of Inadequate Water and Sanitation. The Lancet.

[5] Elsevier B.V. (2016), Addressing governance and management challenges in small water supply systems - the integrity management approach in Kenya. Available at www.sciencedirect.com. Accessed in February 2018.

[6] Elsevier B.V. (2016), Addressing governance and management challenges in small water supply systems - the integrity management approach in Kenya. Available at www.sciencedirect.com. Accessed in February 2018

[7] Flora, D. B. (2018). Statistical Methods for the Social and Behavioural Sciences A Model-Based Approach SAGE Publications.

[8] Freeman MC, Greene LE, Dreibelbis R, Saboori S, Muga R, et al. (2012).Assessing the impact of a school-based water treatment, hygiene and sanitation programme on pupil absence in Nyanza 
Province, Kenya: a cluster-randomized trial. Tropical Medicine \& International Health. 17: 380-391.

[9] George, M. \& Isaac M., (2009). Water Policy, Accessibility and Water Ethics in Kenya, 7 Santa Clara J. Int'l L. 177. Available at: http://digitalcommons.law.scu.edu/scujil/vol7/iss1/3 12th November 2017

[10] Githuku, C. (2009). Assessment of the Environmental Risks of Wastewater reuse in Urban and Peri-urban Agriculture in Nairobi. MSc Thesis, JKUAT.

[11] Government of Kenya -Transition Authority (2015). Draft final report on functional analysis and competency assignment of functions in the water sector. Nairobi.

[12] Jasper C, T., Bartram, J., (2012).Water and Sanitation in Schools: A Systematic Review of the Health and Educational Outcomes. International Journal of Environmental Research and Public Health 9: 2772-2787.

[13] Kenya Bureau of Statistics (2010). Kenya 2009 Population and housing census highlights. Retrieved from www.Planning.go.ke. 16th February 2017.

[14] Kenya National Bureau of statistics (2016). Bungoma County multiple cluster survey 2013/2014 final report. Nairobi. Kenya

[15] Kenya National Bureau of Statistics. (2010). Kenya 2009 Population and housing census highlights. Retrieved from www.Planning.go.ke. 10th Jan 2018

[16] Kombo, D.K and Tromp D.L (2006). Introduction to Research Methodology. Pauline's Publications Africa, Nairobi, Kenya.
[17] Kwena, R. \&Moronge, M. (2015). Determinants of sustainability of rural water projects in Kenya: a case study of the Netherlands Development Organization (SNV) supported water schemes in Kajiado County. The Strategic Journal of Business and Change Management, 2(2)(124), 2025-2077.

[18] Lucie L, Nzioki R, Feuerstein L (2016) Addressing Governance and Management Challenges in Small Water Supply Systems The Integrity Management Approach in Kenya. Aquatic Procedia Volume 6, Pages 39-50

[19] Muganda O. M. \&Mugenda A.G., (1999), Research Methods. Quantitative and Qualitative Approaches. African Centre for Technology Studies (ACTS).Nairobi.

[20] Nyanchaga, E. N (2011). Importance of Water in Kenya Challenges and Reforms. University of Nairobi, Kenya.

[21] UNDP (2007). Improving Water Governance in Kenya through Human Rights Based Approach. A Mapping and Baseline Report.: http://ebookbrowse.com/baseline-report-hrba-kenya-pdfd107548951.

[22] Water Kenya report (2006), Kenya National Water Development Report 2nd UN World Water Development Report 'Water: A shared responsibility UN-WATER/WWAP/2006/12

[23] Water Services Regulatory Board (WASREB), (2009). Water and Sanitation Coverage in Kenya. Impact report, Nairobi.

[24] Water Services Regulatory Board (WASREB), (2009). Water and Sanitation Coverage in Kenya. Impact report, Nairobi.

[25] Wayne K. Hoy, Curt M. Adams (2015). Quantitative Research in Education Second Edition SAGE Publications. 